\title{
EL IMPULSO RENOVADOR DEL AMERICANISMO DURANTE LA SEGUNDA REPÚBLICA: TEMAS COLONIALES EN LA REVISTA TIERRA FIRME
}

\author{
Carmen de Mora \\ Universidad de Sevilla \\ demora@us.es
}

RESUMEN / ABSTRACT

En este artículo se examina la revista española Tierra Firme (1935-1937) atendiendo, en primer término, al contexto de la política cultural de carácter regeneracionista que, tras la crisis finisecular, se propuso restablecer los vínculos con las repúblicas hispanoamericanas. En segundo lugar, tras una descripción de las características más significativas de la revista, así como del equipo de colaboradores que trabajó en ella, se comentan algunas muestras representativas de artículos y reseñas sobre temas coloniales organizados en tres apartados: fuentes documentales, crónicas de Indias y otros textos coloniales y, por último, artículos en los que prevalece un enfoque transatlántico.

Palabras Clave: Segunda República, política cultural, temas coloniales, relaciones trasnacionales.

In this article, the Spanish magazine Tierra Firme (1935-1937) is examined, paying attention, in first place, to the context of cultural politics of regenerational character that planned to reestablish the bonds with the Spanish American republics, after the turn-of-the-century crisis. In the second place, after a description of the magazine's most significant characteristics as well as the team of collaborators working in it, some representative samples of articles and reviews about colonial topics are commented, which are organized in three sections: documentary sources, chronicles of the Indies and other colonial texts and, finally, articles with a predominant transatlantic focus.

KEY WORDS: Second republic, cultural politics, colonial topics, transnational relations. 
La creación de la revista Tierra Firme (1935-1937) fue resultado de la feliz convergencia de un grupo selecto de estudiosos y del apoyo oficial recibido gracias a la política cultural de la Segunda República. Profundizar en sus orígenes y en su lectura nos ilustra sobre la génesis de un americanismo liberal en España.

Después de la crisis moral y política del 98, es conocido que el inicio del siglo XX fue un período de cambios sociales en España marcado por la industrialización y la modernización de la sociedad, los desplazamientos de la población rural hacia las ciudades, la secularización y la reducción del analfabetismo. Un afán de renovación y de estar al día favoreció la penetración de corrientes intelectuales procedentes de Alemania, Francia e Inglaterra. Tales factores dieron lugar, durante las primeras décadas del siglo XX, a un florecimiento cultural, conocido como la Edad de Plata, que se veía reflejado en las producciones artísticas y literarias, en los periódicos y revistas y, en fin, en numerosos ámbitos del conocimiento. Contribuyeron de manera notable a esa modernización social la reforma educativa llevada a cabo por la Institución Libre de Enseñanza, creada por Francisco Giner de los Ríos en 1876, e iniciativas como la creación en 1907 de la Junta de Ampliación de Estudios (JAE), que desempeñó un papel preeminente en el diseño de la política cultural de España con el extranjero y hacia América ${ }^{1}$, si bien en el balance final, debido a la escasez de medios, los resultados no fueran los previstos: "Su logro más notable radicó en poner en valor el cambio modernizante que en esos años se produjo en España, proyectando hacia América una imagen que la homologaba con los países europeos más desarrollados" (Sepúlveda 60). Ese mismo organismo creó, a su vez, el Centro de Estudios Históricos de Madrid y la Residencia de Estudiantes, dos de las instituciones que contribuyeron a consolidar la reforma cultural emprendida

El surgimiento de las políticas culturales en Europa se produjo al final de la Gran Guerra, cuando las relaciones internacionales entraron en una nueva fase y los Estados se implicaron directamente en la vida cultural de sus respectivos países. A través de los ministerios de relaciones exteriores se fueron creando en Francia, Alemania, la Unión Soviética e Italia, entre otros países, organismos cuya función era principalmente promover la difusión de la cultura nacional en el exterior como medio de influencia. En ese contexto, aun en condiciones desfavorables, también en España se tomaron medidas para fomentar las relaciones culturales con el extranjero que se canalizaron a través de los servicios diplomáticos. En esa labor fueron ciertos sectores intelectuales los que llevaron la iniciativa aprovechando el impulso regenerador de la Institución Libre de Enseñanza. Ver Delgado Gómez-Escalonilla (9 y ss.) y Sepúlveda (60-61). 
por la JAE. Vinculada al Centro de Estudios Históricos, en el marco de las medidas que se tomaron a partir de 1911 para favorecer las relaciones científicas con los países americanos de lengua española, se creó la Escuela de Filología Española ${ }^{2}$ constituida por un equipo de filólogos reunidos en torno a Menéndez Pidal. La Revista de Filología Española (1914) fue su órgano de expresión y en ella empezó a manifestarse una proyección americanista mediante la colaboración de Alfonso Reyes, primero, y de Pedro Henríquez Ureña algo más tarde ${ }^{3}$. Las Instituciones Culturales Españolas en América - cuyo modelo podría considerarse la de Buenos Aires, donde se fundó el Instituto de Filología de la Universidad de Buenos Aires (1923) ${ }^{4}$ - permitieron desarrollar la orientación americanista de la Escuela de Filología Española y canalizarla a través de la actividad docente e investigadora, cuyas aportaciones fundamentales sobre el estudio del español de América sentaron las bases para trabajos posteriores (García Mouton 163-184). Por tanto, dentro del proceso regeneracionista que se inició en España tras la crisis finisecular el restablecimiento de los vínculos culturales con Hispanoamérica fue una tarea prioritaria.

La voluntad de impulsar la proyección internacional de España mediante el factor cultural dio lugar a la creación, dentro del Ministerio de Estado (ME), de una Oficina de Relaciones Culturales Españolas (ORCE), en 1921, que

2 Fue la sección más importante del CEH. Menéndez Pidal contó con colaboradores de la talla de Américo Castro, Tomás Navarro Tomás, Federico de Onís y Antonio García Solalinde (Bernabéu y Naranjo 56).

Las disposiciones tomadas por la JAE para favorecer el intercambio universitario entre España y los países americanos tuvieron su contrapartida en las instituciones que se crearon en la otra orilla: La Institución Cultural española de Buenos Aires (1914), la Institución Cultural Española del Uruguay (1918), el Instituto de Filología de la Universidad de Buenos Aires (1923), el Instituto Hispano-Mexicano de Intercambio Universitario (1925), el Departamento de Estudios Hispánicos de la Universidad de San Juan de Puerto Rico (1927), creado por indicativa de del rector Thomas E. Benner y Federico de Onís, y el Instituto de las Españas de New York, a cargo de Federico de Onís (Véase Bernabéu y Naranjo 31 y ss., y Granados 103-124). Los dos ejes básicos de las acciones en América eran el Instituto de Filología de la Universidad de Buenos Aires y el Departamento de Español de la Universidad de Puerto Rico (...). A ellos habría que sumar el del Instituto de las Españas y la Institución Cultural Española de Nueva York (Granados 174).

El primero en dirigirlo fue Américo Castro, discípulo de Menéndez Pidal. Como publicación oficial del Instituto apareció la Revista de Filología Hispánica (1939-1946), dirigida por Amado Alonso, de características similares a la creada en España por Menéndez Pidal. 
completaría las funciones desempeñadas por la JAE y actuaría en coordinación con ella. La iniciativa fue promovida por Américo Castro, gran conocedor de las cuestiones relativas a la política cultural exterior ${ }^{5} \mathrm{y}$, en coincidencia con las ideas de Altamira, entre sus objetivos figuraba recuperar el prestigio cultural entre las repúblicas hispanoamericanas. Para ello se programaron diversas acciones que contemplaban el apoyo a instituciones culturales ya existentes en ambos lados del Atlántico, entre ellas, el intercambio de profesores ${ }^{6}$, la atracción de estudiantes hispanoamericanos, convenios de carácter académico, difusión de libros y publicaciones periódicas, y la promoción de artistas y compañías dramáticas españolas ${ }^{7}$. No otra era la visión de Luis de Zulueta, quien llegó a ser Ministro de Estado de la Segunda República con el gobierno de Azaña (1931-1933). En un artículo titulado "La política exterior de la República" (Tierra Firme, 1935, no 3$)^{8}$, al tratar de las relaciones con las naciones hispanoamericanas las enfocaba como un problema espiritual antes que económico:

Los problemas hispanoamericanos, pues, se sitúan en el terreno de la cooperación intelectual y de la labor cultural. Publicaciones, revistas internacionales en nuestra lengua, discursos, conferencias, trabajos científicos emprendidos en común, instituciones para la investigación científica o para la enseñanza, cambio de profesores y cambio de alumnos, congresos universitarios, reuniones pedagógicas entre los educadores de los distintos países que integran nuestra familia de naciones (23).

Pensaba Zulueta que tal empresa era necesaria para que la República española completara su labor interna de reconstrucción nacional con una obra exterior "de gran aliento y vasto porvenir". En ese contexto hay que situar el proyecto

5 Llegó a desempeñar el cargo de embajador de la República española en Berlín desde abril de 1931 hasta febrero de 1932.

6 El propio Castro, durante la dictadura de Primo de Rivera, pudo viajar a Hispanoamérica para impartir cursos y conferencias, lo que le permitió conocer de cerca países como Argentina, Chile, México, Puerto Rico y Cuba.

7 Para una relación más completa de las medidas que se tomaron véase Delgado Gómez-Escalonilla 24-25.

8 Todas las citas de la revista Tierra Firme están tomadas de la edición facsimilar en 8 volúmenes (Madrid: Sociedad Estatal de Conmemoraciones Culturales -CSIC- Publicaciones de la Residencia de Estudiantes, 2008). Dicha edición lleva un excelente estudio introductorio e índices, a cargo de Salvador Bernabéu Albert y Consuelo Naranjo Orovio. 
de Tierra Firme concebido por Américo Castro. Durante la Segunda República, gracias al aumento del presupuesto destinado al Centro de Estudios Históricos, se originaron tres nuevas secciones ("Literatura Contemporánea", "Estudios clásicos" y "Estudios americanos", dirigida esta última por Américo Castro y conocida más tarde por el nombre de "Sección Hispanoamericana") y se editaron diversas publicaciones periódicas, una de ellas fue la revista Tierra Firme (1935-1937). Tanto la Sección Hispanoamericana como la revista fueron creadas por la Junta de Relaciones Culturales ${ }^{9}$. A la política cultural de la Segunda República se debió igualmente la creación, en 1931, de un Centro de Estudios de Historia de América en la Universidad de Sevilla, dirigido por el historiador José María Ots Capdequí, discípulo de Rafael Altamira y colaborador de Tierra Firme.

La Sección Hispanoamericana (1933-1938) del Centro de Estudios Históricos estuvo integrada en un principio por un reducido número de colaboradores de Castro especialistas en estudios lingüísticos y literarios: Ramón Iglesia ${ }^{10}$, su esposa Raquel Lesteiro y Ángel Rosenblat. Ellos se ocuparon de los estudios americanistas durante el curso 1934-1935; más adelante se unieron al grupo el salvadoreño Rodolfo Barón Castro, Antonio Rodríguez Moñino, el mexicano Silvio A. Zavala y Manuel Ballesteros Gaibrois. Todos ellos, animados por Américo Castro, integraron la redacción de la revista. Varios de los estudiosos que colaboraron en ella se habían formado en las clases de doctorado que impartía Rafael Altamira ${ }^{11}$, catedrático de Historia de las Instituciones de América, en la Facultad de Derecho de la Universidad Central

9 Este organismo había sido creado con el nombre de Oficina de Relaciones Culturales Españolas, pero durante la dictadura de Primo de Rivera se transformó en la Junta de Relaciones Culturales (diciembre de 1926).

10 Leoncio López-Ocón Cabrera reivindica la labor desarrollada por los representantes del americanismo liberal, como Iglesias, y recoge el testimonio de Ramón Ezquerra Abadía, primer bibliotecario del Instituto Fernández de Oviedo, sobre el "ninguneo" que se practicó con Iglesias Parga ante la falta de reconocimiento de su obra (López-Ocón 391).

11 Desde muy pronto mostró Rafael Altamira su preocupación por la regeneración de España. Tras haber ganado la cátedra en la Universidad de Oviedo, en 1897, le fue encargado preparar el discurso de inauguración del curso siguiente. En él animaba a sustituir el pesimismo por una actitud positiva que restituyera el crédito de nuestro pasado histórico y señaló la importancia de las élites formadas en la Universidad para esta tarea. Entre las numerosas cuestiones que trató en aquel discurso una de las más importantes fue la necesidad de fortalecer los lazos con las naciones hispanoamericanas (véase Abellán 23 y ss.). Sobre estas ideas de Altamira y sobre su teoría americanista consúltese el estudio riguroso y esclarecedor de Eva $\mathrm{M}^{\mathrm{a}}$ Valero, Rafael Altamira y la "Reconquista espiritual” de América. 
de Madrid, de las que resultaron valiosas investigaciones y un utilísimo fichero a disposición de todos los investigadores:

El fichero era muy completo, pues a los autores clásicos -como Las Casas, Oviedo, Sahagún, etc. -se unían otros cronistas y autores contemporáneos españoles que tratasen indirectamente de la colonización americana. Gracias a estos materiales se pudieron realizar trabajos tan completos como los del peruano Raúl Porras Barrenechea o los del mexicano Zavala. (...) Estos volúmenes, que se gestaron en realidad en las clases de Altamira, ayudaron a cimentar los nuevos estudios americanistas del Centro de Estudios Históricos (Bernabéu y Naranjo 100).

Hacia mediados de 1935, Castro ya había llevado a cabo con éxito los objetivos que se había trazado. Había creado una sección dedicada a Hispanoamérica para que en España pudieran formarse especialistas; y también una revista y una colección de monografías. Los temas americanistas de los que se ocuparon principalmente fueron: cartografía, demografía, arqueología, edición crítica de textos y estudios históricos sobre instituciones coloniales ${ }^{12}$. La nueva sección creada por Castro fue presentada en el XXVI Congreso Internacional de Americanistas, celebrado en Sevilla en aquel mismo año. ${ }^{13}$ Cuatro miembros del grupo que intervinieron como ponentes publicaron sus trabajos en la revista Tierra Firme, ya que la edición de las Actas se retrasó

12 Esas eran también las cuestiones que dominaban el americanismo internacional (Bernabéu y Naranjo 107).

13 Tuvo lugar en Sevilla, del 12 al 20 de octubre de 1935. Ballesteros Gaibrois hizo una detallada reseña de este Congreso en Tierra Firme $\left(n^{\circ} 4,1935\right)$. El Comité español estuvo presidido por Gregorio Marañón y colaboraban con él Rodríguez de Viguri, Ots y Capdequí, Ballesteros-Beretta, Torroja y Castañeda. Dado que el evento se celebró en Sevilla, el interés recayó en los problemas del descubrimiento, de la conquista y la colonización. El tema que más repercusión tuvo entre los congresistas fue El Descubrimiento de América desde el punto de vista de la valoración de sus fuentes y la figura más controvertida resultó el Padre Las Casas, cuyo valor historiográfico fue puesto en duda por el Dr. Carbia (véase al respecto el artículo de Emiliano Jos (Tierra Firme $\mathrm{n}^{\circ} 1$, 1936) sobre el XXVI Congreso). Para Ballesteros el valor fundamental del Congreso consistió quizá en haber revelado a España en el campo del americanismo y señalar el renacimiento de una España americanista, pues, en efecto, después de las iniciativas que se llevaron a cabo a raíz de la conmemoración del IV Centenario del descubrimiento de América y de los grandes encuentros que se celebraron, el interés por lo americano había decaído: "Y esto sucedía cuando naciones o grupos científicos, más apartados históricamente, intensificaban su producción americanista" (Tierra Firme n 4, 1935, 134). 
trece años: Ramón Iglesia ("Bernal Díaz del Castillo y el popularismo en la historiografía española"), Ángel Rosenblat ("Los otomanos y taparitas de los Llanos de Venezuela. Estudio etnográfico y lingüístico"), Juan Dantín Cereceda ("Atlas histórico de la América hispano-portuguesa") y Manuel Ballesteros Gaibrois ("Pieles pintadas de bisonte"). La guerra civil impidió que la sección continuara desarrollándose, pues una buena parte de sus miembros se exiliaron y se dispersaron. Ballesteros Gaibrois, que se alineó en las tropas franquistas, fue el encargado de organizar el Instituto Gonzalo Fernández de Oviedo en el Nuevo Consejo Superior de Investigaciones Científicas.

La aprobación de la publicación de la revista tuvo lugar en la reunión de la Junta de Relaciones Culturales del 5 de julio de 1933. Fue una revista de carácter trimestral de la que solo se imprimieron cuatro números en 1935 y otros cuatro en $1936^{14}$, pues dejó de editarse como consecuencia de la Guerra Civil ${ }^{15}$. El director de Tierra Firme fue el poeta y crítico literario Enrique Díaz Canedo ${ }^{16}$. El primer número de 1935 contenía cuatro secciones: Sumario, Investigación, Documentos y Notas. A partir del segundo número se añadió la sección "América en las Revistas", donde se ofrecía un índice de revistas que trataban sobre temas americanos con una selección de los artículos más importantes publicados en las mismas. En el número 4 de 1935, y en los números 1 y 2 de 1936 se suprimen las secciones de Investigación y Documentos y se mantienen las demás. Los números 3-4 de 1936 constan de Sumario, Miscelánea, Notas Bibliográficas y Testimonios. Estos últimos representan un balance de la labor cultural desarrollada por la República Española realizado mediante distintas firmas: A. Ballesteros Usano, A.

14 En siete entregas, ya que los dos últimos se editaron en un solo volumen.

15 Aunque figura con la fecha de 1936, el último volumen de la revista, que incluye los números 3-4, se imprimió en 1937, en Valencia, adonde se había trasladado la revista.

16 En el año 1935 aparecía también como jefe de redacción, pero solo en el volumen $1^{\circ}$, José Fernández Montesinos, y, como secretario, Antonio Morón (en los tres primeros volúmenes). En los números 1 y 2 del año 1936, además del director, figuraban J. Francisco Cirre, como secretario, y Manuel Ballesteros-Gaibrois, R. Barón Castro, Américo Castro, Ramón Iglesia, Antonio R. Rodríguez Moñino, Ángel Rosenblat y Silvio A. Zavala, como redactores. En el número 2 de 1936 el equipo se amplía. El consejo directivo estaba formado por Américo Castro, Enrique Díez Canedo, Genaro Estrada, Fernando Ortiz, Alfonso Reyes y Ricardo Rojas. El redactor jefe era Ramón Iglesia Parga, Manuel Ballesteros-Gaibrois, el secretario, y Rodolfo Barón Castro, J. Dantín Cereceda, V. Loriente Cancio, Antonio R. Rodríguez Moñino, Ángel Rosemblat, Silvio A. Zavala, los redactores. Por último, en los números 3-4 de 1936 ya no figura ningún nombre para los cargos de director y secretario. 
Bernárdez, José María Ots, Luis Santillano, Timoteo Pérez Rubio, T. Navarro Tomás, Emilio G. Nadal, Teresa Andrés, A. R. Moñino, María Zambrano y Enrique Naval.

El número 1 de 1935 va precedido de una declaración de principios en la que se describen los objetivos de la revista, su carácter pluridisciplinar, las características del público al que va dirigida y donde se define su actitud. El objetivo principal era ser espíritu de las principales publicaciones literarias o científicas sin dejar de lado "ninguna aportación fundamental entre las manifestaciones múltiples del pensar de nuestros días" y ofrecer un campo abierto a todas las tendencias, "en donde se contrasten depuradas de sus movimientos apasionados". Estaba destinada a un público hispanohablante interesado en obtener una información precisa y un índice de temas diversos. Para ello, reconocidos especialistas abordaban los problemas españoles y del mundo hispano, así como las tendencias del pensamiento universal que el hombre moderno necesitaba conocer; pues la idea era que España, tras el desastre del 98, dejara de permanecer aislada y saliera del ensimismamiento, que se integrara con su gran familia cultural; en suma, definía su actitud como "un mediador de buena fe". Otro de los valores que se perseguían era la búsqueda del rigor: "Queremos sustituir la retórica y divagación con que se han tratado los más vitales temas hispánicos por el dato exacto y la comprensión más severa" (6). Y puede decirse que lo cumplió con creces. Cabe entender el título desde un punto de vista geográfico y también en sentido literal. El primero se refiere al nombre que se le dio en los primeros tiempos del descubrimiento a la parte continental del Nuevo Mundo situada al sur de las Antillas. El segundo tiene el sentido de bases sólidas y de seguridad. Sin embargo, al comienzo de esta declaración de principios se explica que el título Tierra Firme tiene el sentido de aspiración "más que de seguridad y confianza en sí misma", lo que evocaría el deseo de los españoles que viajaban a América de llegar a tierra y olvidar la larga e insegura travesía marina ${ }^{17}$.

De la lectura detenida de la revista se desprende que los autores e intelectuales que la dirigieron y los que colaboraron en ella adoptaron un enfoque bastante avanzado y certero, muy acorde con las orientaciones que se dieron a nivel

17 Apuntan Bernabéu y Naranjo que "en principio no se editó como revista americanista, sino como puente cultural entre España y América. Así ocurrió durante el primer año de la publicación trimestral, pues al año siguiente sí se convirtió en el Órgano de la Sección Hispanoamericana, como empezó a rezar su subtítulo (128-129). 
internacional, sobre todo si se tiene en cuenta que la tradición americanista en España era relativamente reciente. Además, la participación de especialistas hispanoamericanos satisfacía la actitud dialogante con América que era uno de los principales objetivos de la revista. Por razones de extensión, me limitaré a comentar algunas muestras representativas de artículos y reseñas sobre temas coloniales publicados en Tierra Firme.

\section{UNA TOMA DE CONCIENCIA AMERICANISTA. LAS FUENTES DOCUMENTALES}

No es un hecho casual que la mayor parte de los artículos y notas de carácter americanista publicados en la revista tuviera que ver con la época virreinal. Unos años antes, Rafael Altamira, uno de los principales ideólogos del americanismo en aquellos tiempos, en el discurso que pronunció en la Universidad de Oviedo con motivo de la inauguración del curso 1898-1899, titulado "El Patriotismo y la Universidad"18, había planteado que una de las condiciones imprescindibles para la regeneración nacional de España era restaurar el crédito de nuestra historia, vindicar la historia intelectual y civilizadora de España para la resolución del problema presente y para salir del pesimismo que afectaba a la sociedad y, principalmente, a la clase intelectual española. En este sentido, frente a las críticas demoledoras de algunas potencias europeas movidas por intereses económicos, defendió en diversos escritos la empresa colonizadora española en América, aun reconociendo los errores del pasado, y sostuvo la necesidad de un acercamiento entre España y las repúblicas hispanoamericanas para recuperar la confianza ${ }^{19}$. En concordancia con estas

18 El discurso se imprimió, en tres entregas, con el título de "El patriotismo y la Universidad" en el Boletín de la Institución Libre de Enseñanza (1898). $\mathrm{M}^{\mathrm{a}}$ Dolores de la Calle Velasco señala la huella en este discurso de Discursos a la nación alemana (Madrid, 1899), de Fichte, que Altamira había traducido (véase prólogo a La huella de España en América, n.19, XV).

19 A propósito del hispanoamericanismo, precisa Sepúlveda: “como movimiento su objetivo explícito era la articulación de una comunidad trasnacional sostenida en una identidad cultural basada en el idioma, la religión, la historia, las costumbres o usos sociales. Esa "comunidad imaginada" pretendía reunir a España con el conjunto de las repúblicas americanas, otorgándole a la antigua metrópoli un puesto al menos de primogenitura, cuando no de ascendente" (Sepúlveda 76). 
ideas, dos de los objetivos principales eran contribuir a "la organización y metodización de los estudios americanistas científicamente considerados" y "continuar la obra de vindicación de España en lo que se refiere a su actuación colonizadora" (Altamira y Crevea, La huella 5). Para conseguir el primero de ellos proponía ligar las cátedras y centros de investigación españoles al Archivo de Indias, con objeto de que se llevaran a cabo las necesarias investigaciones, y reorganizarlo científicamente de modo que pudiera cumplir la función que le correspondía, "el Archivo de Indias debía ser la verdadera Casa de América en el orden de las investigaciones históricas" (Altamira y Crevea, La huella 29), "el centro espiritual de los americanistas" (32). En suma, todo estaba por hacer en la apreciación crítica de las fuentes documentales.

Siguiendo de cerca el programa trazado por su maestro, José María Ots, en el artículo titulado "Sevilla y la moderna historiografía hispanoamericana" $\left(\mathrm{n}^{\mathrm{o}} 3,1935\right)$, directamente relacionado con su actividad al frente del Centro de Estudios de Historia de América, de Sevilla, creado durante la Segunda República ${ }^{20}$, presta atención a los fondos, manuscritos o impresos conservados en el Archivo General de Indias, en el Archivo de Protocolos y en la Biblioteca Colombina de Sevilla, los tres faros de la investigación americanista en la ciudad hispalense, y evalúa el extraordinario interés de dichas fuentes documentales para futuros estudios. Se refiere, además, a otra institución sevillana, el Instituto Hispano-Cubano de Historia de América $^{21}$, como un ejemplo a seguir en la preservación sistemática de fondos documentales. Fue iniciativa de Rafael González Abreu, vizconde de los Remedios, la fundación de este centro en el antiguo convento de los Remedios. Contaba con una Biblioteca especializada en la historia de América, en general, y, más específicamente, en la historia de Cuba durante el período post-colombino. El personal del Instituto elaboró inventarios sistemáticos de los libros y manuscritos de interés para la historia de América conservados en las bibliotecas Colombina, Universitaria de Sevilla y la de la Facultad de Filosofía y Letras. Se inició la catalogación de legajos en el Archivo General de Indias, en el Archivo de Protocolos Hispalense y en los Archivos más importantes de Córdoba y su provincia. Enumera asimismo los estudios históricos realizados en el Archivo

20 Después de la guerra civil, el centro se transformaría en la Escuela de Estudios Hispano-Americanos.

$21 \quad$ Para obtener información sobre este Centro puede consultarse El Instituto HispanoCubano de Historia de América (Sevilla), Madrid/Barcelona/Buenos Aires, Compañía Iberoamericana de Publicaciones [1931?]. 
de Protocolos y en el Archivo Municipal, ambos de Córdoba, por José de la Torre, sobre Garcilaso de la Vega, el Inca, y sobre Jiménez de Quesada, el fundador de Nueva Granada.

Otro organismo fue el Centro de Estudios de Historia de América de la Universidad. Continuador oficial de las actividades historiográficas iniciadas por el Instituto Hispano-Cubano, estaba destinado principalmente a actividades de carácter docente de nivel universitario para la formación de nuevos investigadores sobre los problemas fundamentales de la historia de América $^{22}$. Resultado de la labor investigadora del Centro fue la tesis doctoral $^{23}$ del historiador argentino Rómulo D. Carbia sobre la Crónica oficial de Indias ${ }^{24}$, trabajo que, sin embargo, mereció una reseña no muy favorable de Ramón Iglesia, publicada en el número 2 (1935) de Tierra Firme. Iglesia reconocía la sólida documentación manejada por Carbia, pero criticaba la visión unilateral que ofrecía de la historia y que contrastaba con la expresada por Fox Morcillo en su De Historiae Institutione: "La historia como exaltación de valores vitales, en un ansia de inmortalidad" (209) ${ }^{25}$. La actitud de Iglesia es la misma que mantuvo el grupo con respecto al trabajo científico y que se percibe en las numerosas notas y comentarios publicados durante los dos años de vida de la revista: la voluntad de anteponer el rigor y el espíritu crítico a la complacencia.

Gracias a los ficheros del Instituto Hispano-Cubano de Historia de América, B. Bernal Ulecia, que trabajaba por entonces en la biografía de Hernando

22 Completa esta información una relación de las publicaciones de carácter histórico planificadas o ya editadas y el proyecto de una Revista Española de Historia de América. Véase Valdés 199.

23 La tesis fue defendida el 7 de diciembre de 1933, y el tribunal estuvo formado por Jorge Guillén, José María Ots Capdequí, Juan de Mata Carriazo, Juan Tamayo y José de la Peña. Dos años más tarde regresó a Sevilla como delegado de la Universidad Nacional de La Plata y ponente en el XXVI Congreso Internacional de Americanistas, presidido por Gregorio Marañón.

24 Se publicó con el título de La crónica oficial de las Indias Occidentales. Estudio histórico y crítico acerca de la historiografía mayor de Hispano-América en los siglos XVI a XVIII. Con una introducción sobre la crónica oficial de Castilla.La Plata, 1934. Biblioteca de Humanidades, vol. XIV.

25 Iglesia cita un párrafo de Fox Morcillo en latín cuya traducción en castellano es la siguiente: "Al mirar el origen de la historia, me parece que la causa de su creación fue el que los hombres quisieron conocer no sólo la suya sino la de sus mayores y aquellos que eran tenidos en gran estima, y esto por un apetito de honor e inmortalidad que en todos existe por naturaleza" (Fox Morcillo 14). 
Colón, localizó un documento revelador que servía para aclarar relaciones y situaciones económicas en la familia de los Colón. Como se sabe, una de las tareas que realizaba el Instituto, bajo la dirección de Ots Capdequí, consistía en inventariar los documentos conservados en el Archivo de Protocolos que fueran de interés para la historia de América. De ese modo pudo encontrar "una escritura de concierto o concordia celebrada entre los hermanos don Diego y don Hernando Colón, en la Coruña, el 12 de mayo de 1520"26.

Hernando Colón había llegado hasta La Coruña con la escuadra del rey Carlos I, a quien solía acompañar en sus viajes al extranjero, antes de zarpar rumbo a Flandes. Supone Bernal Ulecia que Hernando debió hablarle a su hermano, virrey de las Indias, de su mala situación económica y reclamarle la parte que le correspondía de la herencia de su padre. De ahí que en la escritura Diego Colón se comprometiera a fijarle a su hermano una pensión anual vitalicia pagadera por semestres a cambio de la renuncia de su hermano a la herencia. Sin embargo, como demuestra el autor, tres años más tarde, en su segundo testamento, Diego Colón disponía que se buscara ese contrato entre sus papeles y que se cancelara cuando él muriera porque no quería dejarle esa carga a su sucesor. "No creemos nosotros - escribe Bernal Uleciaque esta cláusula fuese debida a motivos de desafecto. Y no lo creemos por actos realizados posteriormente por el mismo virrey, que demuestran hasta la saciedad el gran cariño y el alto concepto en que tenía a su hermano" (307). A través de la revisión de varios documentos se afianza en la tesis de que los pleitos en que se vieron envueltos los miembros de la familia Colón se debieron a la injusta situación económica que padecían habida cuenta de la posición social relevante que ocupaban. Sostiene, además, que las relaciones entre los hermanos Diego y Hernando nunca se entibiaron: Hernando fue albacea de su hermano y, después de la muerte de este, intervino siempre activamente en el mejor desarrollo de los famosos pleitos colombinos. Al final del artículo aporta un apéndice documental que consta de la citada escritura de concordia y una Real Cédula de confirmación del documento anterior, firmado en Madrid, el 3 de marzo de 1525.

Otra muestra del interés por las fuentes documentales son las reseñas de los catálogos de manuscritos que se iban publicando: dos de manuscritos americanos que complementaban la importante serie madrileña de manuscritos de América: Manuscritos de América (Catálogo de la Biblioteca de Palacio t. 
IX), Madrid, Talleres de Blass, 1935, a cargo de Jesús Domínguez Bordona ${ }^{27}$, y Catálogo de los manuscritos de América existentes en la "Colección de jesuitas" de la Academia de la Historia, Badajoz, "La Minerva Extremeña", $1935^{28}$. Barón Castro dio cuenta $\left(\mathrm{n}^{\circ} 1,1936\right)$ de la publicación, en 1935, de dos nuevos tomos de las series parejas que el Instituto Hispano-Cubano de Historia de América iba editando sobre catálogos de documentos relativos a América: Documentos americanos del Archivo de protocolos de Sevilla. Siglo XVI (Madrid) y Catálogo de los fondos cubanos del Archivo General de Indias. Tomo II. Expedientes diarios. 1642-1799 (Sevilla). El primero fue editado por el Comité organizador del XXVI Congreso internacional de Americanistas ${ }^{29}$; el segundo catálogo se debió al trabajo realizado por José María de la Peña y de la Cámara, profesor de la Universidad hispalense y del Centro de Estudios de Historia de América. Barón dedica también un comentario a la publicación Arte en América y Filipinas (Publicación de la Universidad de Sevilla), Cuaderno I. Sevilla, 1935. Reconocía que el americanismo no había llegado a tomar cuerpo en España, como sí había ocurrido en otros países, a pesar de disponer de elementos fundamentales para la investigación americanista. Una situación que ahora consideraba superada, como demostraba la publicación objeto de la reseña. Se trataba del primero de los cuatro cuadernos anuales sobre Arte en América y Filipinas que el Centro de Estudios de Historia de América de la Universidad de Sevilla, en colaboración con el Laboratorio de Arte de la Facultad de Filosofía y Letras, había proyectado publicar bajo la dirección de Diego Angulo Iñiguez.

En el ámbito hispanoamericano, con motivo del IV Centenario de la ciudad de Lima, en 1935, se editaron dos tomos de Monografías históricas sobre la ciudad de Lima y los Libros de Cabildos de Lima, descifrados y anotados por Bertrán T. Lee, con prólogo de Riva Agüero, publicados en cinco volúmenes. Dichos tomos comprenden las actas de los libros de Cabildos de Lima de los años 1534 a 1561, con vistas a abarcar también las actas de la primera mitad del siglo XVII. Silvio Zavala, que se hizo cargo de la reseña, valora el enriquecimiento de las fuentes municipales de la colonización española

27 Reseñado por Rodolfo Barón Castro (nº4, 1935).

28 Reseñado por Antonio Rodríguez Moñino (n4, 1935).

29 Barón Castro elogia la labor desempeñada por José María Ots Capdequí en la dirección del Instituto, ya que la riqueza del archivo de Protocolos apenas era conocida hasta ese momento. 
con esta publicación, que se sumaba a las actas de los cabildos de México, Guatemala, Buenos Aires, etc., ya publicadas con anterioridad ${ }^{30}$.

\section{CRÓNICAS DE INDIAS Y OTROS TEXTOS COLONIALES}

El grupo de Tierra Firme -y su entorno intelectual- había tomado conciencia de que una de las deficiencias a subsanar en el ámbito del americanismo era el estudio y edición de las crónicas de Indias. Ya Altamira, en una comunicación leída en el Congreso de Historia y Geografía hispano-americanas (Sevilla, 1914), titulada "La condición inicial para escribir la historia americana", había llamado la atención sobre la necesidad de llevar a cabo un estudio crítico de las crónicas ${ }^{31}$ en cuanto "fuentes originales" para contrarrestar la utilización interesada que algunos países europeos hicieron de la historiografía americanista. Y citaba los nombres de los más representativos cultivadores de la bibliografía americanista que le habían precedido en ese mismo afán: Juan Bautista Muñoz, en el prólogo de su Historia del Nuevo Mundo (1793), Navarrete, en la introducción a su Colección de los viajes y descubrimientos (1825) y Harisse, en el prólogo a su Bibliotheca Americana Vetustísima.

Por su parte, Ramón Iglesia, en las palabras que escribió a propósito de una reseña al libro de J. Eric Thompson, traducido al francés y editado por Payot, La civilisation aztèque (Mexico before Cortez, en versión original), a semejanza de Altamira, se lamenta del olvido en que habían permanecido los textos cronísticos, resaltando su interés para el conocimiento de la historia:

Resulta doloroso para nosotros, vernos obligados a buscar en inglés o francés libros que, como éste que nos ocupa, se han hecho con materiales españoles. Salvo uno o dos capítulos, todo lo demás ha sido compuesto, según lo hace constar el mismo Thompon, utilizando a nuestros cronistas de los siglos XVI y XVII. Los nombres de Torquemada, Durán, Sahagún, Bernal Díaz del Castillo, asoman

$30 \quad\left(n^{\circ} 1,1936\right)$.

31 Al hablar de exigencias críticas, Altamira se refería a aspectos como la historia externa de cada libro, sus ediciones y variantes (La huella 59). En esa misma comunicación enumera cada una de las cuestiones que debía plantearse el estudioso que se adentrara en el estudio americanista de las crónicas y cita algunos de los trabajos meritorios que se habían llevado a cabo en ese dominio (Confróntese La huella 59-62). 
a estas páginas, en las que de continuo se extractan sus noticias y descripciones" ( $\mathrm{n}^{\mathrm{o}} 4$ de 1935, 150).

Precisamente en ese mismo número publicaba Iglesia su "Bernal Díaz del Castillo y el popularismo en la historiografía española"32, presentado en el XXVI Congreso de Americanistas. Conocía bien la obra de Bernal porque -como se sabe- estaba preparando junto con su esposa, Raquel Lesteiro, una edición crítica de la Historia verdadera, labor para la que contaron con la valiosa colaboración de Rodríguez Moñino ${ }^{33}$.

El autor parte de una idea tomada de Huizinga, según la cual la historia es la que más se acerca a la vida de todas las ciencias. Esta premisa se cumpliría a rajatabla en el caso español, de forma que - a su juicio- "nuestras producciones históricas más valiosas son las que se han escrito al filo de los hechos, las que han nacido de una visión directa, de una vivencia de los acontecimientos relatados" (5). Pone como ejemplo el fracaso de las crónicas oficiales de Indias frente a las escritas por quienes fueron testigos de los hechos, y va rastreando otros muchos ejemplos sacados de las obras históricas españolas, desde la época medieval, que corroboran su punto de vista. Los casos antitéticos de Gonzalo Fernández de Oviedo y Pedro Mártir de Anglería, de un lado; de Bernal Díaz y López de Gómara, de otro, vendrían a confirmarlo.

El núcleo del artículo lo constituye su defensa de la Historia verdadera escrita por Bernal, frente a las acusaciones de los historiadores que, por el contrario, juzgaron acertado el dictamen de Antonio de Solís, amparado en una tesis aristocratizante -que contraponía el héroe, Cortés, frente al vulgo-,

32 (n 4, 1935). El artículo fue recogido más tarde en el libro de Iglesia El hombre Colón y otros ensayos, junto con otros tres artículos sobre Bernal: "Las críticas de Bernal Díaz a la Historia de la Conquista de México de López de Gómara", "Introducción al estudio de Bernal Díaz del Castillo y de su Verdadera Historia” y "La Historia Verdadera de Bernal Díaz del Castillo". Aunque en el primero de ellos critica a Bernal por su fobia desmedida contra Cortés y contra Gómara, y rectifica la defensa incondicional que hacía del autor de la Historia verdadera frente a Gómara en el artículo de Tierra Firme, aquellas primeras observaciones siguen siendo válidas en cuanto a las diferencias entre los dos tipos de crónicas.

33 A causa de la guerra civil, Iglesia no pudo concluir la edición, se alistó en el ejército republicano, y, al terminar la guerra, se exilió a Francia; emigró después a México y años más tarde a Estados Unidos. En 1945 el Instituto Gonzalo Fernández de Oviedo publicó el primer volumen de la edición crítica de la Historia verdadera, pero sin que figurara el nombre de Iglesia Parga, ni tampoco los de Raquel Lesteiro y Rodríguez Moñino. En 1967, el CSIC editó la obra, en dos volúmenes, preparados por Carmelo Sáenz de Santamaría, por lo que los nombres de quienes habían trabajado originalmente en la edición quedaron solapados. 
sobre las razones que animaron a Bernal Díaz a escribir su crónicas ${ }^{34}$, actitud que le lleva a preferir el trabajo de Cunnighame Graham sobre el cronista, antes que el de Prescott. Para Iglesia, la imagen de Cortés que ofrece Bernal, a diferencia de la de Solís, es válida por ser humana, sin idealizaciones: "Y Solís, que calzaba el coturno a Cortés, no podía ignorar que el calzado usado por el caudillo y sus soldados en la conquista era la alpargata" (Iglesia 16). En segundo lugar, sale al paso de la acusación hecha por Genaro García, editor de la crónica, a Bernal, al afirmar que "rebaja a los indios y encumbra a los españoles más de lo debido", y considera más humana la conducta de los conquistadores que "la de cualquier tropa colonial de nuestros días" (17).

La conclusión a la que llega Iglesia es que a partir de los Reyes Católicos, y más concretamente, con las crónicas de Indias, la tendencia culta que se había mezclado con la popular en Pero López de Ayala (s. XIV) se rompe a favor de la última y, especialmente, con la prosa de Bernal; pero la situación cambió en el siglo XVII con la excesiva preocupación por la forma, y "la historiografía popularista ya no levantará cabeza. Quedó enterrada en América con los soldados que la escribieron" (18).

Aunque más tarde rectificara algunas de estas ideas en otro artículo ${ }^{35}$, Iglesia reconoció unos valores en la Historia verdadera que son los que le dan relevancia a este texto en el imaginario sobre la conquista, los mismos que más tarde recuperaron grandes novelistas hispanoamericanos, como Azuela o Fuentes.

Antonio R. Rodríguez Moñino ${ }^{36}$ escribe una nota esclarecedora motivada por una publicación de Clemente Palma sobre Don Alonso Henríquez de Guzmán y el primer poema sobre la conquista de América. Rodríguez Moñino

$34 \quad$ "Pero aunque le asiste la circunstancia de aver visto lo que escribió, se conoce de su misma obra que no tuvo la vista libre de passiones para que fuesse bien governada: muéstrase tan satisfecho de su ingenuidad como quexoso de su fortuna; andan entre sus renglones muy descubiertas la envidia y la ambición; y paran muchas vezes estos afectos destemplados en quexas contra Hernán Cortés, principal héroe desta historia, procurando penetrar sus designios para deslucir y enmendar sus consejos (...)" (Antonio de Solís, Historia de la conquista de México. Barcelona: 1711, 5. Datos tomados de Ramón Iglesia, Tierra Firme, 1935, nº 4: 10).

$35 \quad$ Me refiero al artículo "Las críticas de Bernal Díaz del Castillo a la Historia de la Conquista de México, de López de Gómara” ya citado.

36 En 1935 ganó la plaza de catedrático de Lengua y Literatura Españolas y empezó a colaborar en el Centro de Estudios Históricos, y ese mismo año fue nombrado redactor de la revista Tierra Firme. Es encomiable su intensa labor en la custodia de archivos y bibliotecas públicas y privadas; uno de sus más importantes hallazgos fue el descubrimiento, en casa 
rectifica la opinión de Clemente Palma sobre cuál era el poema más antiguo relativo a la conquista de América -para el erudito limeño era La Araucanay señala el trabajo publicado por José Toribio Medina: El primer poema que trata del descubrimiento del Nuevo Mundo (Santiago de Chile, 1916). Se refería a Carlo Famoso de Luis Zapata, impreso en Valencia, en 1566, poema que el autor había empezado a escribir trece años antes. A continuación se refiere a otro dato aportado por Clemente Palma: Nueva obra y breve en metro y prosa sobre la muerte del Adelantado D. Diego de Almagro, hecha por un testigo de vista por los años 1550. Los dos textos que se conocen de este poema no llevan nombre de autor ni fecha: uno está inserto en la Vida y hechos de D. Alonso Henríquez de Guzmán, y fue publicado por los compiladores de la Coldoin en 1886; el otro se conserva en un manuscrito del Archivo de Indias, y existe una copia moderna en la Biblioteca Nacional de Lima. Palma argumenta que el poema pertenece a Henríquez de Guzmán, pero Rodríguez Moñino, basándose en diversos datos que lo contradicen, lo considera anónimo y demuestra que la Nueva obra es el primer poema que se ocupa de la conquista, anterior, por tanto, en tres años a Carlo Famoso de Luis de Zapata.

No ofrece menos curiosidad el artículo de Rodríguez Moñino sobre "Cómo se publicaba un libro en Indias a principios del siglo XVII. Andanzas inquisitoriales de La Ovandina, crónica de linajes coloniales" (1936, nos. 3-4). Las dificultades a las que se veían sometidos los escritores de la época colonial cuando querían publicar sus obras en el Nuevo Mundo ha sido una cuestión ineludible al hablar de la literatura de ese período, sobre todo cuando se buscaban argumentos para explicar la escasez de novelas. Los trámites por los que debía pasar un libro antes de su publicación eran la censura, la Licencia Real, la tasa y la intervención del Corrector. En Indias, la dificultad se incrementaba a causa de la escasez de imprentas, de ahí que en los círculos literarios coloniales la publicación de un libro en varios tomos, cuando su contenido no era exclusivamente religioso, como de costumbre, constituía un acontecimiento muy comentado, según explica Rodríguez Moñino. Eso sucedió con los cuatro tomos del libro de genealogías que se disponía a dar a la prensa, en Lima, Pedro Mexía de Ovando. Tras haber pasado con éxito la censura de Don Alonso Bravo de Sarabia y Sotomayor, perteneciente al

del murciano José Alegría, de un manuscrito, desconocido hasta ese momento, de la Historia verdadera de la conquista de la Nueva España de Bernal Díaz. 
Consejo del rey, oidor de la Real Audiencia y Cónsul de la Inquisición, y de haber obtenido la licencia del Príncipe de Esquilache, La Ovandina, título de la obra, pasó al taller del impresor limeño Jerónimo Contreras, quien lo dio a la luz en 1621. Enseguida empezaron las murmuraciones y las críticas por diversos motivos, inclusive empezó a circular un romance anónimo que acusaba a Ovando de haber recibido buenas cantidades de dinero por haber incluido en su libro a algunas personas. Informado el Santo Oficio, tras comprobar la veracidad de las acusaciones, ordenó que se retirasen los ejemplares, los cuales pasaron a manos de los inquisidores. Para que examinase las materias de Fe, el Tribunal comisionó a fray Antonio de Peñaranda y para las noticias históricas y genealógicas tocantes a la limpieza de sangre, al licenciado D. Gaspar de Valdespina. Rodríguez Moñino comenta detalladamente los informes de uno y otro. Al ver los resultados tan negativos para su libro Mexía de Ovando decidió marcharse a Nueva España para imprimir allí el resto y presentar una apelación en Madrid contra las acusaciones de que aquel había sido objeto. Los inquisidores limeños, al conocer las intenciones del autor les escribieron a los colegas mexicanos para ponerlos en antecedentes y también al Consejo de la Santa General Inquisición, en Madrid, para que resolviese. Al parecer, los censores de Madrid se divirtieron con ambos, con la obra y con los informes:

Fr. Diego de Barrasa y Fr. Francisco Verdugo reciben juntamente la voluminosa Ovandina y el nada flaco informe de la Inquisición de Lima. Y si les divirtió la obra con su sarta de genealogías absurdas y disparatadas, no menos tuvieron que reír con el informe. ¡Cuánto distingo, cuánta sutileza lógica, cuánto argumento, silogismo y retorcimiento de frase, cuánta cita de teólogos, cuánto Santo Padre traído al retortero para destruir las esperanzas económicas de un pobre diablo! (427-428).

A pesar de que la censura de Barrasa y Verdugo fue exculpatoria con Ovando, no se permitió la circulación del libro; reunido el Supremo Consejo mandaron que se recogiesen los ejemplares que todavía se conservaban en Lima, lo que las autoridades limeñas cumplieron con creces:

Este fue el broche puesto por la burocracia -escribe el crítico- a una aventura de la que un pícaro español en Indias aguardó un día obtener provechos, gloria, gratitud y unos quilates de nobleza, no por ilegítimamente adquiridos menos gratos en una época vanagloriosa y pagada de la sangre azul: en los principios del fin español (431). 
El mismo Rodríguez Moñino, en “¿Una crónica dominicana del siglo XVI?”37, comenta una curiosa anécdota ocurrida en un lago de la isla Española, tomada del Jardín de flores curiosas de Antonio de Torquemada, quien dice a su vez haberla tomado de una crónica que hizo un alcalde de Santo Domingo. Deja constancia de ella por aportar un dato más para el estudio del elemento fantástico en la conquista y colonización de América.

Poco considerada hasta ahora como modalidad discursiva, el diario, sin embargo, es una fuente de gran valor para el estudio de la sociedad colonial. Silvio A. Zavala reseña el Diario de Lima de Juan Antonio Suardo (1629-1634) ${ }^{38}$, correspondiente a las anotaciones que, por cédulas de 16 de Diciembre de 1623 y 23 de Noviembre de 1631, se ordenó registrar sobre los acontecimientos diarios que ocurriesen en el virreinato del Perú. Este diario fue hallado por Rubén Vargas Ugarte en el Archivo de Indias, gracias a una indicación del investigador argentino Torre Revello. Menciona Zavala otros volúmenes similares como el Diario de José y Francisco de Muguburu, publicado por el Concejo Provincial de Lima y editado por Carlos A. Romero; y el mexicano Diario de Sucesos Notables, por D. José Manuel de Castro Santa Ana (1752-58), publicado por Genaro García en sus Documentos Inéditos o muy raros para la Historia de México (México, 1854).

Mucho antes de que el tema de la comida se pusiera de moda con los llamados estudios culturales, Juan Dantín Cereceda redactó un sustancioso estudio sobre los "Primeros contactos entre los tipos de alimentación antillano y mediterráneo" 39 que resulta paradigmático de este tipo de trabajos. Se basa en la certeza de que cada dominio geográfico se puede caracterizar por una masa de alimentos que proporciona el propio medio, aunque ello no impide que se enriquezca con nuevos alimentos ya sea a través de la conquista o del comercio pacífico. Así, repasa la presencia de los alimentos mediterráneos fundamentales, el pan, el vino y el aceite de oliva, sirviéndose de diversos textos, literarios unos y de carácter más historiográfico otros: el Cantar de Mio Cid, El Sacrificio de la Misa de Gonzalo de Berceo, la Historia General y Natural de las Indias de Fernández de Oviedo, El sí de las niñas

38 Publicado por el Concejo Provincial de Lima, IV Centenario de la Fundación de la Ciudad. Con introducción y notas por Rubén Vargas Ugarte, Lima: 1935. La reseña figura en la sección de "Notas" (nos. 3-4 de 1936).

39 (1936, nos. 3-4). 
de Moratín, Vida del almirante de Hernando Colón, la Historia de las Indias de las Casas y los testimonios reunidos por Fernández de Navarrete en los Viajes de Cristóbal Colón, por citar algunos de los más representativos. A través de estos últimos, sobre todo de los relatos de Colón, el autor evoca el descubrimiento sorprendente de alimentos americanos llevado a cabo por los españoles que llegaron a las Antillas. Y si en el primer viaje todavía se resistieron a introducir los alimentos indígenas en su dieta, en el segundo, debido a las circunstancias se fue relajando poco a poco la resistencia: "La fusión de ambas alimentaciones, la antillana y la mediterránea, que se elabora en el curso de los años 1493-1496, está ya consumada al terminar este segundo viaje" (412).

\section{UNA ACTITUD TRANSATLÁNTICA}

Por razones obvias, los aspectos jurídicos de la conquista han sido siempre una de las vertientes más cultivadas del americanismo, $y$, dado que varios colaboradores de Tierra Firme habían estudiado Derecho-Silvio A. Zavala, José María Ots, Rodolfo Barón Castro y Antonio Rodríguez Moñino, entre otros-, hay varios artículos sobre esta especialidad en las páginas de la revista. Aquello que más llama la atención es el acierto de enfocar los aspectos tratados tendiendo puentes entre ambos continentes, no por simples razones de confraternización sino por una búsqueda de rigor, pues una de las líneas de actuación de estos estudiosos, en cualquier dominio, era la reescritura de la Historia depurándola de prejuicios, errores e interpretaciones alejados de otros intereses que no fueran el propósito de conocer en la medida de lo posible la verdad de los hechos ${ }^{40}$. Un ejemplo representativo de la mirada solo incluye la primera entrega de Ángel Rosenblat sobre "El desarrollo de la población indígena de América" -que continuó en los números 2 y 3 de 1935. En las conclusiones que obtiene Rosenblat de su extenso estudio, juzga que las apreciaciones de los contemporáneos, cronistas e historiadores principalmente, que jugaban con los millones, están falseadas por distintos motivos, o bien para exaltar la obra misionera de una orden (Juan Díez de la Calle o Pedro Fernández de Quirós), o bien para destacar el valor de los soldados o su maestría de capitán (Hernán Cortés), o para engrandecer e idealizar el pasado indígena (Clavigero) o por espíritu polémico y defensa apasionada de la causa de los indios (Las Casas). Frente a las 
transatlántica que imperaba en este grupo es el libro de Silvio A. Zavala, Las instituciones jurídicas en la conquista de América ${ }^{41}$, del que da cuenta la reseña de Santiago Magariños ${ }^{42}$. Fue el primer volumen perteneciente a la Sección Hispanoamericana del Centro de Estudios Históricos y en él Zavala se proponía estudiar las principales ideas e instituciones jurídicas que influyeron en el desarrollo de la conquista de América por los españoles. Al valorar el aspecto jurídico de aquel período reconocía que merecía estudiarse dentro de la historia jurídica de España, ya que procedía de la rama medieval del Derecho español, si bien señalaba la posibilidad -hasta entonces no explorada- de indagar en la transformación de esas viejas instituciones españolas trasladadas a tierras americanas. La contribución de Zavala en este ámbito consistía en considerar el tema de la conquista y de la primera colonización como base del Derecho indiano y a la vez como antecedente de las instituciones de la América independiente. La diferencia entre la actitud de los historiadores españoles y la de Zavala era que los primeros enfocaban la cuestión teniendo en el punto de mira los orígenes españoles exclusivamente, mientras que para Zavala y otros investigadores americanos esos orígenes constituían la "base primera del Derecho que las tierras americanas han vivido hasta hoy" (211). Por haberse desenvuelto entre ambos mundos, Zavala supo renovar con un enfoque más ecuánime y actualizado para su época la vertiente jurídica de la conquista y colonización.

En concordancia con este mismo tema, apareció en Tierra Firme ${ }^{43}$ la comunicación presentada por Ots en el XXVI Congreso Internacional de Americanistas con el título de "La expansión del derecho español en las Indias", donde desarrolla algunas observaciones sobre las características que presenta

exageraciones de cronistas y viajeros, para las estadísticas consideraba más objetivo recurrir al número de pobladores, censos parciales, repartimientos de indios realizados al día siguiente de la conquista y en ocasiones la magnitud de los ejércitos. Y tiene en cuenta el desarrollo histórico, el medio de vida de las poblaciones precolombinas y los restos arqueológicos de sus culturas.

41 Centro de Estudios Históricos. Sección Hispanoamericana. Vol. I. Madrid: 1935.

42 Este profesor falangista ocupó en 1940 la cátedra de Historia de la Universidad de Madrid y, poco después, la presidencia del Instituto de Cultura Hispánica. Fue desposeído de sus cargos por autorizar la publicación de un libro del poeta Miguel Hernández y se vio obligado a exiliarse a Venezuela, donde prosiguió su carrera académica desarrollando una importante labor docente e intelectual. Fundó el Instituto de Arte de la Facultad de Humanidades y Educación de la Universidad Central de Caracas.

${ }^{43} \quad \mathrm{n}^{\circ} 1$ de 1936. 
la expansión del Derecho español peninsular en los territorios de las Indias occidentales a lo largo del período colonial. Observaba Ots que, a pesar de que el Estado aplicaba en las Indias el mismo régimen municipal que había establecido en la metrópoli, en la práctica existían notables diferencias no ya con la metrópoli, sino entre los distintos virreinatos, y lo mismo sucedía con el sistema de Encomiendas. De ahí que al final de su estudio reclame que los estudios históricos del derecho hispanoamericano del período colonial se realicen no sobre las base de las fuentes legales, sino con el complemento obligado y esencial de los documentos de aplicación del derecho. Para esta tarea era necesaria la colaboración de todos los investigadores de los países hispanoamericanos, con la finalidad de que se pudieran contrastar las informaciones contenidas en las series documentales conservadas en el Archivo General de Indias con las que se encuentran en los archivos judiciales y de Protocolos de las naciones americanas (87).

En la misma línea se sitúa el estudio comparativo de Silvio A. Zavala entre "Las conquistas de Canarias y América", que publicó en dos entregas ${ }^{44}$. Basó el estudio en la existencia de un nexo de continuidad entre ambas conquistas, pues, a su juicio, los Reyes Católicos encauzaron las empresas españolas en América mediante normas muy similares a las aplicadas en la conquista de Canarias; no obstante, debido a las diferencias espacio-temporales, experimentaron cambios significativos que él se encargó de precisar.

Junto con los aspectos jurídicos, las cuestiones lingüísticas estuvieron en el foco de atención tanto en lo referente a las lenguas indígenas ${ }^{45}$ como a la evolución del español de América. Con motivo de la publicación de $E l$ problema de la lengua en América ${ }^{46}$, de Amado Alonso, escribió Américo Castro una reseña que aprovechó para entrar en el debate y reflexionar sobre una cuestión que trascendía lo puramente lingüístico y concernía a lo que él

$44 \quad$ La primera parte apareció en el $n^{\circ} 4$ de 1935 y la segunda, en el no 1 de 1936. En 1991 fue reeditado por el Cabildo Insular de Gran Canaria.

$45 \quad$ Véase el extenso artículo de Ángel Rosenblat titulado "Los otomanos y taparitas de los llanos de Venezuela. Estudio etnográfico y lingüístico", que fue publicado en tres entregas -la primera apareció en el n ${ }^{\circ} 1$ de 1936-y del que ya había presentado un resumen en el XXVI Congreso Internacional de Americanistas. Rosenblat, basándose en dos vocabularios inéditos de la Biblioteca del Palacio Nacional de Madrid, llevó a cabo un estudio comparativo entre la lengua de los otomanos y la de los taparitas intentando ubicarlas en el cuadro lingüístico del continente.

46. Madrid: Espasa-Calpe, 1935. 
denominaba "lo hispánico". Llamaba la atención Alonso en el libro sobre el "relajamiento social del sentido de la norma" que se había producido en Buenos Aires a causa de la oleada de inmigración extranjera que invadía la ciudad y que había dado lugar en la vida colectiva a una especie de "lingua franca" caracterizada por la ausencia de normas reguladoras. Por su parte, Castro ya había tratado el tema en unos artículos suyos publicados en $\mathrm{El} \mathrm{Sol}^{47}$ acerca del uso del lunfardo y la aspiración a una lengua nacional argentina: atacaba a aquellos que defendían los giros vulgares y el lunfardo para adoptar un idioma peculiar con el propósito de separarse del idioma peninsular, afirmar la independencia lingüística y, con ella, la nacional, pues pensaba que solo dentro del castellano podía Argentina continuar modelando su fisonomía nacional: "Rojas, Lugones, Larreta, Gálvez, Capdevila, Obligado, Gerchunof, la Storni, Ghiraldo, Luisa Israel, Borges y cien más que acuden al azar de la memoria (...) figurarán en la literatura de lengua española, o castellana, según ellos prefieren" (184). En la situación idiomática argentina, distinguía entre un idioma conversacional "angostado y pobre" y la lengua literaria, que seguía el desarrollo del idioma en España. Y termina el artículo reclamando para Argentina el rechazo del fantasma de la lengua nacional $\mathrm{y}$, por contra, propone nacionalizar a base del castellano de Sarmiento. No hace falta recordar que estas mismas ideas desarrolladas con más amplitud en La peculiaridad lingüística rioplatens $e^{48}$ recibieron una crítica irónica y mordaz de Borges en "Las alarmas del doctor Américo Castro"49.

Por último, me referiré a un curioso artículo del poeta vanguardista Juan Larrea, cuya vinculación con el Perú está asociada principalmente a la amistad, llena de admiración, que le unía a César Vallejo: "Un vaso peruano del museo de Madrid" (nos. 3-4, 1936). En este trabajo revela su interés apasionado por las piezas arqueológicas, las cerámicas, los metales y maderas de origen precolombino. Su aportación consistía en las distintas interpretaciones y teorías existentes sobre los orígenes y elementos decorativos de un vaso de cerámica peruano conservado en el Museo Arqueológico Nacional de Madrid, mediante

47 Madrid, el 22 y el 25 de septiembre de 1927. Castro consideraba que las ideas contenidas en esos artículos eran como un prólogo adventicio y pospuesto al libro de Alonso.

48 Buenos Aires: Losada, 1941.

49 Está incluido en Otras inquisiciones, Buenos Aires: Sur, 1952. Más tarde, Piglia, sin citar a Castro, retomó la discusión, actualizándola y reorientándola hacia la revisión del canon literario argentino, a partir del uso de la lengua y del estilo, en la segunda parte de Respiración artificial (1980). 
una donación del Gobierno de Perú, tras haberse exhibido en la exposición celebrada con motivo del Cuarto Centenario del descubrimiento de América. Emprende Larrea esta labor por considerar que hasta ese momento no se había logrado la verdadera comprensión del objeto y que su estudio podía enriquecer el conocimiento de la más brillante de las culturas del antiguo Perú: la nazca. El escritor llega al convencimiento de que el motivo decorativo consistía en un extraordinario instrumento de terror, después de cotejarlo con una descripción que aparece en las noticias ofrecidas por el conquistador Alonso de Mesa en la Información que por mandato del virrey Toledo se realizó en el Cuzco el 22 de febrero de 1572: "Tan estrecha es la correspondencia existente entre este texto y la representación del vaso, que bien podría pasar ésta por una simple ilustración de aquél" (519). Al interés del artículo, de indudable alcance antropológico, se unen las curiosas circunstancias que le llevaron a escribirlo y el hecho de que se publicara precisamente en Tierra Firme. En 1930, Larrea viajó a Perú y quedó tan fascinado por las culturas andinas que en dos meses se gastó todo el dinero de la herencia que acababa de recibir en piezas arqueológicas incaicas ${ }^{50}$. La colección, constituida por más de 600 piezas, se exhibió primero en Francia, en 1933, y, al saberlo, el gobierno republicano invitó a Larrea a exponerla en España. Así, la exposición "Arte Inca" fue inaugurada por el presidente de la República, Niceto Alcalá Zamora, el 15 de mayo de 1935 en la Biblioteca Nacional de Madrid. Ese mismo año, el XXVI Congreso Internacional de Americanistas editó un libro de la colección, que también había sido expuesta en Sevilla, titulado Arte peruano $^{51}$. Ante tan exitosa acogida el poeta optó por dejarla en depósito que se creara un Museo de Indias, al crearse oficialmente, mediante decreto, el Museo y Biblioteca de Indias (41). Para un desarrollo detallado de este viaje y de cómo formó Larrea su colección, véase el artículo de Jorge Gutiérrez Bolívar.

51 Con motivo de la exposición, en las conclusiones del Congreso se aprobó la necesidad de constituir en España un Museo y una Biblioteca de Indias, un proyecto que fue asumido por el gobierno. La base del Museo estaría formada por los fondos de la Sección Etnográfica Americana y Filipina del Arqueológico Nacional y la colección de Larrea, además de otros fondos existentes en depósitos del Estado. En cuanto a la Biblioteca, estaría integrada por fondos impresos y manuscritos de la sección Ultramar de la Biblioteca Nacional; de la Hispanoamericana del mismo establecimiento, así como "fondos que puedan ser desglosados tanto de la Nacional, como de otras bibliotecas" (véase la pormenorizada relación que hace de dichos fondos Rodríguez Moñino, Tierra Firme nos. 3-4, 1936: 609). Así, en 1937, en plena guerra civil, el gobierno creó el Museo-Biblioteca de Indias, pero la guerra y la derrota 
en el Museo Arqueológico Nacional de Madrid, es decir seguía siendo el propietario, pero la cedía para su gestión y exhibición (Gutiérrez Bolívar 10). El 14 de abril de 1937, en apoyo de la República, Larrea decidió donar su colección de antigüedades incaicas al pueblo republicano español porque quería marcar "la relación existente entre el destino del Nuevo Mundo del porvenir y el de la República nacida en España" ${ }^{52}$.

\section{CONCLUSIÓN}

Ha pasado casi un siglo, y a quien todavía no haya leído la revista le sorprenderá la actualidad de muchos de sus planteamientos. El afán de universalidad y el entusiasmo americanista que animaba el proyecto de Tierra Firme, el espacio preferente que se les daba a las fuentes documentales existentes en archivos y bibliotecas sobre la época colonial, el interés por la edición y estudio de las crónicas de Indias, la perfecta integración en sus páginas de colaboradores españoles e hispanoamericanos, así como la aplicación de enfoques transatlánticos; la calidad, en suma, de los artículos y reseñas que se publicaron en ella la convierten en una de las muestras más representativas del americanismo progresista español. Prueba de ello es que algunos de aquellos artículos han seguido reeditándose años más tarde. Con el estallido de la guerra civil, la revista dejó de publicarse, pero el proyecto americanista republicano que había propiciado su creación dejó sentadas algunas bases en la Península y, sobre todo, seguiría dando sus frutos en tierras americanas a través de los españoles en el exilio.

\section{BIBLIOGRAFÍA}

Abellán, José Luis. Rafael Altamira. Madrid: Agencia Española de Cooperación Internacional para el Desarrollo, 2012.

Altamira, Rafael. "El patriotismo y la Universidad”. Boletín de la Institución Libre de Enseñanza (1898), 22, 462: 257-270; 22, 463: 291-296; 22, 464: 323-327.

republicana impidieron que el proyecto pudiera llevarse a efecto. Un reflejo de aquél fue la creación, en 1941, del Museo de América por parte del Gobierno vencedor.

52 A partir de 1965, la colección se trasladó al actual Museo de América. 
Altamira y Crevea, Rafael. La huella de España en América [1924]. Introducción de M ${ }^{\mathrm{a}}$ Dolores de la Calle Velasco. Salamanca: Ediciones Universidad de Salamanca, 2008.

Bernabéu, Salvador y Consuelo Naranjo. Historia contra la "Desmemoria" y el olvido: el americanismo en el Centro de Estudios Históricos y la creación de la revista Tierra Firme (1935-1937). Estudio introductorio. Tierra Firme edición facsimilar en 8 volúmenes. Madrid: Sociedad Estatal de Conmemoraciones Culturales -CSIC- Publicaciones de la Residencia de Estudiantes, 2008.

Delgado Gómez-Escalonilla, Lorenzo. Imperio de papel. Acción cultural y política exterior durante el primer franquismo. Madrid: CSIC, 1992.

El Instituto Hispano-Cubano de Historia de América (Sevilla). Madrid/ Barcelona/ Buenos Aires: Compañía Iberoamericana de Publicaciones [1931?].

Fox Morcillo, Sebastián. Diálogo para la enseñanza de la Historia. Traducción, edición crítica, notas y revisión del texto por Antonio Cortijo Ocaña para la web: http://www.proyectos. cchs.csic.es/humanismo y humanistas/, Madrid: 2011.

García Mouton, Pilar. "La vocación americanista de la Escuela de Filología Española”. La Junta para Ampliación de Estudios y América Latina: Memoria, política y acción cultural (1907-1939). Coord. Consuelo Naranjo Orovio. Revista de Indias 239 (2007): 163-184.

Granados, Aimer. "La corriente cultural de la JAE en México: El Instituto Hispano Mexicano de Intercambio Universitario, 1925.1931”. La Junta para Ampliación de Estudios y América Latina: Memoria, política y acción cultural (1907-1939). Coord. Consuelo Naranjo Orovio. Revista de Indias 239 (2007): 103-124.

Gutiérrez Bolívar, Jorge. "El legado de Juan Larrea”. Anales del Museo de América 3 (1995): 7-20.

Iglesia, Ramón. El hombre Colón y otros ensayos. México: El Colegio de México, 1944.

Larrea, Juan. Corona Incaica. Córdoba: Universidad Nacional de Córdoba (Argentina), 1960.

López-Ocón Cabrera, Leoncio. "La ruptura de una tradición americanista en el CSIC: la evanescencia de la revista Tierra Firme". Arbor 631/632 (1998): 387-411.

Sepúlveda, Isidro. "La JAE en la política cultural de España hacia América". La Junta para Ampliación de Estudios y América Latina: Memoria, política y acción cultural (19071939). Coord. Consuelo Naranjo Orovio Revista de Indias 239 (2007): 59-80.

Tierra Firme edición facsimilar en 8 volúmenes. Estudio introductorio e índices, a cargo de Salvador Bernabéu Albert y Consuelo Naranjo Orovio. Madrid: Sociedad Estatal de Conmemoraciones Culturales -CSIC-Publicaciones de la Residencia de Estudiantes, 2008.

Valdés, Palmira. La historiografía americanista en España 1755-1936. Madrid/Frankfurt: Hispanoamericana/ Vervuert, 2007.

Valero Juan, Eva Mª Rafael Altamira y la "reconquista espiritual" de América. Prólogo de $\mathrm{M}^{\mathrm{a}}$ Ángeles Ayala. Murcia: Cuadernos de América sin nombre, 2003. 